\title{
Cognitive and behavioral evaluation of nutritional interventions in rodent models of brain aging and dementia
}

\author{
Devin Wahl ${ }^{1,2}$ \\ Sean CP Coogan ${ }^{1,3}$ \\ Samantha M Solon-Biet ${ }^{1,2}$ \\ Rafael de Cabo ${ }^{4}$ \\ James B Haran ${ }^{5}$ \\ David Raubenheimer ${ }^{1,6,7}$ \\ Victoria C Cogger ${ }^{1,2}$ \\ Mark P Mattson ${ }^{8}$ \\ Stephen J Simpson ${ }^{1,2,7}$ \\ David G Le Couteur ${ }^{1,2}$ \\ 'Charles Perkins Centre, University of \\ Sydney, Sydney, ${ }^{2}$ Aging and Alzheimers \\ Institute, ANZAC Research Institute, \\ Concord Clinical School/Sydney \\ Medical School, Concord, NSW, \\ Australia; ${ }^{3}$ Department of Renewable \\ Resources, University of Alberta, \\ Edmonton, AB, Canada; ${ }^{4}$ Translational \\ Gerontology Branch, National \\ Institute on Aging, National Institutes \\ of Health, Baltimore, MD, USA; \\ ${ }^{5}$ Philadelphia College of Osteopathic \\ Medicine, Philadelphia, PA, USA; \\ ${ }^{6}$ Faculty of Veterinary Science, \\ ${ }^{7}$ School of Life and Environmental \\ Sciences, University of Sydney, Sydney, \\ NSW, Australia; ${ }^{8}$ Laboratory of \\ Neurosciences, National Institute on \\ Aging's Intramural Research Program, \\ National Institutes of Health, \\ Baltimore, MD, USA
}

Correspondence: David G Le Couteur C22 - Repatriation General, Concord, The University of Sydney, NSW 2006, Australia

Tel +6I 2976772 I2

Fax+6I 297675419

Email david.lecouteur@sydney.edu.au
This article was published in the following Dove Press journal:

Clinical Interventions in Aging

8 September 2017

Number of times this article has been viewed
Abstract: Evaluation of behavior and cognition in rodent models underpins mechanistic and interventional studies of brain aging and neurodegenerative diseases, especially dementia. Commonly used tests include Morris water maze, Barnes maze, object recognition, fear conditioning, radial arm water maze, and Y maze. Each of these tests reflects some aspects of human memory including episodic memory, recognition memory, semantic memory, spatial memory, and emotional memory. Although most interventional studies in rodent models of dementia have focused on pharmacological agents, there are an increasing number of studies that have evaluated nutritional interventions including caloric restriction, intermittent fasting, and manipulation of macronutrients. Dietary interventions have been shown to influence various cognitive and behavioral tests in rodents indicating that nutrition can influence brain aging and possibly neurodegeneration.

Keywords: calorie restriction, intermittent fasting, aging, memory, macronutrients

\section{Introduction}

The major translational goals in aging research are to extend healthy lifespan and to reduce chronic diseases of aging. Old age is the greatest risk factor for all major causes of mortality and morbidity: cardiovascular diseases, cancers, and in particular the neurodegenerative diseases including movement disorders and dementia. ${ }^{1}$ Most research into dementia has focused on developing pharmacological interventions to treat and prevent cognitive impairment, but despite an extensive international effort, the only medications that are available are cholinesterase inhibitors and memantine, which have modest effects on symptoms but not disease progression. ${ }^{2}$

An alternative approach to prevent the onset of age-related neurodegenerative disease, while simultaneously improving overall health, is nutrition. Nutritional interventions such as caloric restriction, intermittent fasting (IF), and manipulation of macronutrients have often been reported to improve healthspan and lifespan in a variety of organisms and laboratory settings, with increasing evidence that they are effective in humans..$^{3-5}$ Nutritional interventions are readily translatable because they are available to entire populations and have less economic burden and adverse effects associated with prescription medicines. ${ }^{6}$ Yet, the study of nutritional interventions in the context of neurodegenerative disease remains undeveloped.

Rodent models of cognition and behavior have various strengths and weaknesses, particularly in how they reflect human brain aging and cognitive deficits. 
Here, we review the effects of manipulations of nutrient intake on cognition and behavior in rodent models of aging, brain aging and dementia.

\section{Nutritional interventions in aging research}

Three nutritional interventions have been at the forefront of aging research: 1) calorie restriction (CR) - a total reduction by $10 \%-50 \%$ in daily caloric intake without malnutrition; 2) IF - extended periods of food deprivation (typically 16-24 hours) with intervening periods of food intake; and 3) varying macronutrient ratios in ad libitum diets. ${ }^{3,7,8}$

The molecular mechanisms by which those interventions counteract aging are complex, and recent findings implicate nutrient-sensing pathways (eg, sirtuins [SIRT-1], insulin-like growth factor-1 [IGF1], peroxisome proliferator-activated receptor gamma coactivator 1 -alpha [PGC-1 $\alpha$ ], mechanistic target of rapamycin [mTOR], and fibroblast growth factor 21 [FGF21]). ${ }^{9,10}$ The plasticity of these pathways in response to nutritional changes result in reduced levels of inflammation, increased insulin sensitivity, efficient autophagy, and increased cellular stress resistance, all leading to lifespan extension and health benefits in a variety of species. ${ }^{11,12}$

While CR can extend lifespan and counteract many age-related diseases in a wide range of species, it is difficult to implement in humans with essentially unlimited access to calorie-rich food. Another criticism of CR is that health benefits may not be due to a reduction in total calories, but rather a reduction in one or several dietary macronutrients. This line of reasoning grew from the field of nutritional ecology, in which the ratios and amounts of macronutrients in foods, meals, and diets have been shown to exert a driving influence on animal physiology across numerous species. ${ }^{13}$ We recently confirmed this in rodents using a systematic experimental design, where an ad libitum lowprotein, high-carbohydrate (LPHC) diet was shown to be more effective than CR (by dilution with fiber) in improving lifespan and several markers of cardiometabolic health. ${ }^{14}$ Conversely, high-protein, low-carbohydrate diets resulted in reduced lifespan and poorer cardiometabolic health. We hypothesized that reducing protein while simultaneously increasing carbohydrate in the diets functioned in a similar way to $\mathrm{CR}$ and IF by changing the underlying molecular pathways. Specifically, we suggested that high-protein intake coupled with low carbohydrate was detrimental to health possibly due to branched-chain amino acids (valine, leucine, and isoleucine) activating mTOR which subsequently mediated the response between healthspan and lifespan. The mTOR and other pathways, including pathways involving insulin, growth hormone and IGF-1, have been implicated in lifespan in a variety of organisms. ${ }^{15}$ IF can extend lifespan and forestall many age-related disease processes in rodents with minimal overall reduction in caloric intake. ${ }^{7,16}$

Studies have investigated the roles of specific amino acids on healthspan and lifespan, with a focus on branchedchain amino acids, methionine (Met), and tryptophan (Trp). Met restriction has been shown to improve lifespan of yeast and mammalian cells through a mechanism involving reduced amino acid intake and suppression of the mTOR pathway, resistance to stress, and attenuated levels of inflammation. ${ }^{17}$ In rodents, Met restriction reduces mitochondrial oxidative stress and improves insulin sensitivity, with subsequent studies showing lifespan benefits. ${ }^{18}$ There has been limited research on dietary Trp reduction, with results pointing toward reduced inflammation and constraint of cell growth. ${ }^{19}$

While the role of LPHC diets in extending healthspan has begun to be elucidated, there is limited information on potential roles of LPHC diets, Met, and Trp on brain health during aging. Such animal studies manipulated one dietary macronutrient for a short period and then assessed performance in a cognitive task shortly thereafter. A recent study demonstrated that a large increase in only one macronutrient, while keeping the other two at low percentages, exacerbates cognitive decline in a mouse model of Alzheimer's disease (AD). ${ }^{20}$ Similar studies have concluded that each macronutrient plays a critical role in brain health, but it is not known what ratios of macronutrients may be optimal for memory and cognition. However, such "one-nutrient-at-atime" manipulations do not consider the interactive effects of single nutrient manipulations on balance with respect to other dietary components. ${ }^{21}$ There is evidence that the brain, like other physiological systems, requires a target ratio of macronutrients to develop and function optimally, with this ratio changing across the life course and with aging. ${ }^{22}$ The developing brain may be particularly sensitive to macronutrient intake, such that restriction of certain macronutrients during embryonic and early postnatal development can adversely affect cognitive outcomes. ${ }^{23}$

A key concept that has emerged from studies of macronutrient intake is that nutrient sensing pathways responsible for metabolic adaptations also affect brain functionality and the pathogenesis of many different neurological disorders. ${ }^{24}$ 
In the case of energy restriction, we reviewed the effects of $\mathrm{CR}$ and IF on cognitive health during aging in rodents. ${ }^{22}$ In brief, $\mathrm{CR}$ and IF can increase dendritic spine density in hippocampal neurons, improve mitochondrial respiration, promote neuron viability/survival, enhance synaptic plasticity, and regulate genes involved in memory and cognitive function. ${ }^{25} \mathrm{CR}$ and IF have consistently been reliable and robust interventions to hinder neurodegeneration in mouse and rat models of Alzheimer's, Parkinson's, and Huntington's diseases and stroke. ${ }^{26,27}$ A limited number of studies have also demonstrated neuroprotective effects of $\mathrm{CR}$ in non-human primates. ${ }^{28-30}$

Although there is strong evidence that $\mathrm{CR}$ and IF are two of the most effective non-pharmacological or non-genetic treatments to prevent neurodegeneration, there are no studies on the potential benefits of protein restriction (particularly LPHC diets) on brain health during the aging process. Given the robust evidence that long-term LPHC nutritional interventions are beneficial for improving lifespan and metabolic health in rodents, coupled with the fact that those treatments appear to activate similar nutrient response pathways as CR and IF, ${ }^{14}$ it is plausible that LPHC diets may also be beneficial for preventing the onset of neurodegenerative disease.

Many tools and methods have been used to evaluate the effects of macronutrient intake on the aging brain. Here, we review studies in which the impact of $\mathrm{CR}$, IF, and restriction of dietary protein and specific amino acids on cognition have been evaluated in rodents. A better understanding of how nutritional interventions affect aging brain biology might enable the development of specific macronutrient-based interventions to optimize brain health during aging.

\section{Overview of the impact of aging on cognition in rodents}

Extensive research about age-related changes in learning and memory, and underlying cellular and molecular mechanisms has accrued during the past three decades. ${ }^{31-34}$ Memory tests in rodents ideally will parallel those tests commonly used in humans; however, this is not possible because of major species differences in memory and cognition. There are limited animal tests that serve as models for many complex manifestations of dementia such as emotional and language impairment, and executive function. ${ }^{35}$ There are, however, a variety of behavioral assessments (Table 1) that have been developed which are meant to target the same declining memory processes as seen in humans during aging and with dementia diagnoses. ${ }^{36}$

The first types of memory to deteriorate during AD in humans are episodic and semantic memory, while working spatial memory closely follows. These forms of memory are usually affected because of early involvement of the hippocampus and associated long-term potentiation processes. ${ }^{37,38}$ Episodic and semantic memory loss often coincides with lapses in spatial and navigational learning and memory. Spatial learning is a process that involves multiple cognitive and perceptual processes and refers to attaining and maintaining a certain trajectory from one place (or object) to another and is learned over time. Therefore, cognitive-behavioral tasks assessing spatial memory are particularly important in rodent research and are widely used in nutritional interventions. There are a variety of well-established memory-assessing cognitive-behavioral tasks, either at a specific point or over a time course in rodents (Table 2). It is important to assess rodent cognition using behavioral tests that are relatively simple and with low levels of inter-animal variability within a laboratory and high reproducibility between laboratories. However, some learning and memory deficits are subtle; therefore, cognitive tests that are more demanding are often required to discriminate differences between ages and experimental groups of animals. ${ }^{39}$ Testing animals in both negative- and positive-reinforcement paradigms can reduce the effects of

Table I A selection of different types of memory common to both rodents and humans

\begin{tabular}{|c|c|c|}
\hline $\begin{array}{l}\text { Name of memory } \\
\text { process (reference) }\end{array}$ & Examples in rodents & Examples in humans \\
\hline Episodic memory ${ }^{105}$ & $\begin{array}{l}\text { Object recognition, target object recognition, } \\
\text { IntelliCage }\end{array}$ & $\begin{array}{l}\text { Mnemonic memory, remembering past experiences and analyzing } \\
\text { possible future events, information about the order of events }\end{array}$ \\
\hline Recognition memory ${ }^{51}$ & Object recognition, touch screen & Recognition of faces or well-known objects \\
\hline Semantic memory ${ }^{45}$ & Morris water maze, Barnes maze, object recognition & Memory of facts and places \\
\hline Spatial memory ${ }^{40}$ & $\begin{array}{l}\text { Morris water maze, Barnes maze, Y-maze, radial } \\
\text { arm water maze }\end{array}$ & $\begin{array}{l}\text { Navigating through the streets of a hometown, following } \\
\text { directions, navigating around rooms of a house, remembering } \\
\text { where items are placed }\end{array}$ \\
\hline Emotional memory ${ }^{106}$ & Fear conditioning & $\begin{array}{l}\text { Learning to associate cues to negative outcomes, expressing } \\
\text { emotional responses (ie, stress) }\end{array}$ \\
\hline
\end{tabular}


Table 2 Commonly used tasks to assess rodent memory acquisition

\begin{tabular}{|c|c|c|c|c|}
\hline $\begin{array}{l}\text { Name of test } \\
\text { (reference) }\end{array}$ & $\begin{array}{l}\text { Purpose and type } \\
\text { of memory }\end{array}$ & Methodology & Strengths & Weaknesses \\
\hline Water maze $e^{40}$ & $\begin{array}{l}\text { Spatial memory } \\
\text { acquisition, some } \\
\text { working memory }\end{array}$ & $\begin{array}{l}\text { 4-day spatial memory } \\
\text { acquisition followed by probe } \\
\text { trial } 24 \text { hours later }\end{array}$ & $\begin{array}{l}\text { Well-established test } \\
\text { and used in laboratories } \\
\text { across the world, easily } \\
\text { reproducible, simple } \\
\text { procedure }\end{array}$ & $\begin{array}{l}\text { Can be stressful for rodents, } \\
\text { expensive, time consuming, can } \\
\text { only test one rodent at a time, } \\
\text { necessary to have a drainage and } \\
\text { fill system for water, necessary } \\
\text { for video tracking software }\end{array}$ \\
\hline Barnes maze $e^{42}$ & $\begin{array}{l}\text { Spatial memory } \\
\text { acquisition, some } \\
\text { working memory }\end{array}$ & $\begin{array}{l}\text { 4-day spatial memory } \\
\text { acquisition followed by probe } \\
\text { trial } 24 \text { hours later }\end{array}$ & $\begin{array}{l}\text { Less stressful for rodents } \\
\text { utilizing more natural } \\
\text { memory processes, } \\
\text { well established, used in } \\
\text { laboratories across the world }\end{array}$ & $\begin{array}{l}\text { Time consuming, can only test } \\
\text { one rodent at a time, necessary } \\
\text { to have a large room for the } \\
\text { I } \mathrm{m} \text { wide maze and video } \\
\text { tracking equipment }\end{array}$ \\
\hline $\begin{array}{l}\text { Novel object } \\
\text { recognition }^{50,51}\end{array}$ & $\begin{array}{l}\text { Associative memory, } \\
\text { declarative memory, } \\
\text { working memory }\end{array}$ & $\begin{array}{l}\text { 2-day protocol, replace old } \\
\text { object with novel object, } \\
\text { calculate "recognition index" }\end{array}$ & $\begin{array}{l}\text { Well-established test, utilizes } \\
\text { rodents' natural exploratory } \\
\text { processes, cost-effective, } \\
\text { time efficient }\end{array}$ & $\begin{array}{l}\text { Does not assess spatial memory, } \\
\text { possible experimenter bias } \\
\text { in results analysis }\end{array}$ \\
\hline $\begin{array}{l}\text { Fear } \\
\text { conditioning }{ }^{107}\end{array}$ & Associative memory & $\begin{array}{l}\text { 2-day protocol - teach } \\
\text { rodents to associate a "tone" } \\
\text { with a foot shock, learning } \\
\text { measured by freezing behavior }\end{array}$ & $\begin{array}{l}\text { Short-time commitment } \\
\text { from researcher ( } 2 \text { days), } \\
\text { well established in the } \\
\text { literature, robust results }\end{array}$ & $\begin{array}{l}\text { Stressful for rodents, pain factor } \\
\text { involved, expensive equipment, } \\
\text { does not exclusively involve } \\
\text { hippocampus }\end{array}$ \\
\hline $\begin{array}{l}\text { Radial arm } \\
\text { water maze }{ }^{108}\end{array}$ & $\begin{array}{l}\text { Spatial and working } \\
\text { reference memory }\end{array}$ & $\begin{array}{l}\text { Learned location of one of the } \\
\text { eight escape arms, multiple } \\
\text { trials over several days }\end{array}$ & $\begin{array}{l}\text { Well established, natural } \\
\text { exploring tendencies, } \\
\text { short-time commitments, } \\
\text { short training protocol, no } \\
\text { olfactory cues }\end{array}$ & $\begin{array}{l}\text { Can be expensive, swimming } \\
\text { may induce stress, difficult } \\
\text { to set up }\end{array}$ \\
\hline$Y$-maze ${ }^{60}$ & $\begin{array}{l}\text { Active working } \\
\text { short-term memory }\end{array}$ & $\begin{array}{l}\text { Two trials, "spontaneous } \\
\text { alternation" is calculated by } \\
\text { the number of entries into } \\
\text { the novel arm, quantified as } \\
\text { spontaneous alternation }\end{array}$ & $\begin{array}{l}\text { Cost-effective, minimal } \\
\text { training, not time consuming, } \\
\text { natural exploratory behavior } \\
\text { of the animal }\end{array}$ & $\begin{array}{l}\text { Does not measure memory } \\
\text { acquisition over long periods } \\
\text { of time }\end{array}$ \\
\hline
\end{tabular}

confounding factors unrelated to memory, such as sensory or motor function, anxiety, or depression.

\section{Behavioral tests of learning and memory in rodents}

Several experimental tests have been utilized to study the effects of nutrients on cognition and synaptic plasticity (Figure 1).

\section{Morris water maze (MWM)}

The MWM (Figure 1A) tests spatial learning and memory retention in rodents and involves an acquisition phase where the animal learns the location of a "goal or escape platform" target over a period of multiple days. ${ }^{40,41}$ In this test, rodents swim in a circular pool and learn to find a platform which is hidden 1-2 cm below the surface of opaque water. The rodents use cues placed around the room to orient and learn the location of the platform. Memory acquisition is typically measured by how quickly the animals learn to find the platform over designated number of training trials (memory acquisition), and then probe trials are performed (with

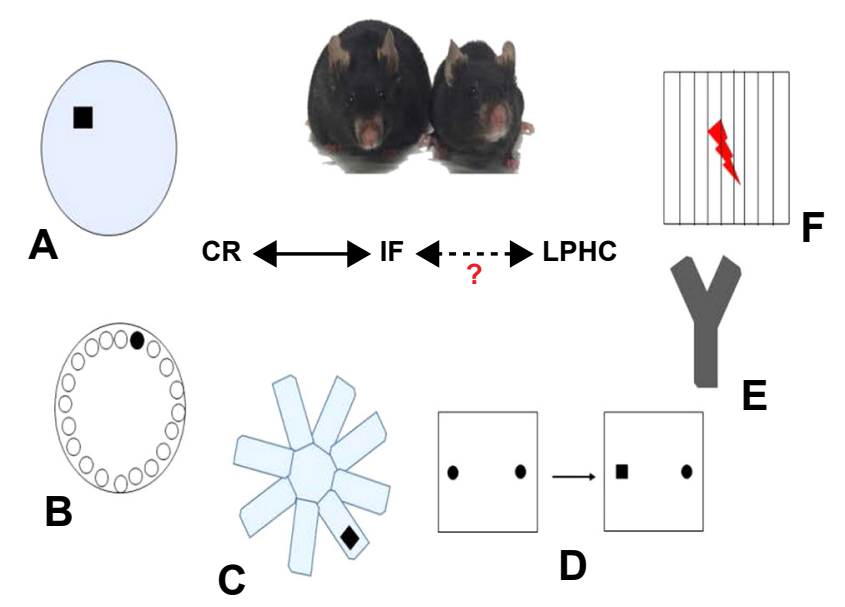

Figure I The most commonly used memory behavioral tests in rodents.

Notes: (A) Morris water maze: rodent learns to find submerged escape platform over time (black indicates escape platform); (B) Barnes maze: rodent learns to find escape box over time (black indicates escape hole); (C) radial arm water maze: rodent learns the location of the correct arm containing the submerged escape platform (black indicates escape platform); (D) novel object recognition: recognition index calculated as a percentage of time the rodent explores the novel object vs the old object on day 2 (black indicates objects, arrow signifies inter-trial interval); (E) Y maze: number of entries into novel arm quantified after brief training period; and (F) fear conditioning: freezing activity calculated after a brief conditioning phase (lines indicate wires, bolt indicates mild shock).

Abbreviations: CR, calorie restriction; IF, intermittent fasting; LPHC, low-protein, high-carbohydrate. 
increasing lag times) in which the platform is removed from the pool and the amount of time the animal spends close to the former location of the platform is determined (memory retention). MWM probe trial results are most typically represented as the percentage of time the animal spends in the target quadrant and the number of entries to the previous location of the platform.

\section{Barnes maze (BM)}

The BM (Figure 1B) was developed based on the same principles as the $\mathrm{MWM}^{42,43}$ but, in contrast to the MWM, imposes little or no stress on the animal because there is no swimming. ${ }^{44,45}$ The test consists of a circular platform comprising 20 equally spaced concentric open holes. Under one of the holes lies a black escape box. Memory acquisition is measured by how quickly it takes the rodent to find the escape box over a 4-day period, and a probe trial is performed 1 day later to assess if the rodent actually learned the task. It is known that high-stress situations increase corticosterone levels in mice, which are inversely correlated with spatial memory acquisition. ${ }^{46}$ For those reasons, the BM is recommended for the study of spatial memory acquisition.

\section{Radial arm water maze (RAWM)}

The RAWM (Figure 1C) test was primarily developed as a spatial and reference memory task, although it may also be used to evaluate working memory. ${ }^{47}$ The RAWM is a popular test because it does not require extensive training and minimizes olfactory cues. ${ }^{48}$ The basic premise of RAWM is that rodents learn to locate a hidden platform in one of the eight arms. After a brief training period, results are quantified by the number of errors (ie, incorrect arm entries) and the number of seconds the mouse takes to reach the escape platform. $^{49}$

\section{Novel object recognition (NOR)}

One of the most popular memory tests in rodents is NOR (Figure 1D) because it parallels similar tests in humans. NOR in mice was predicated upon the primate and human preference to explore a novel stimulus rather than a known one. ${ }^{50}$ This highlights the translational characteristics of the test and takes advantage of the natural tendency of rodents to explore a novel object rather than the one previously present. ${ }^{51}$ The NOR testing protocol is relatively simple, cheap, and quick, thus widely utilized. ${ }^{52}$ After a short period of habituation to the study arena (typically a box with opaque walls), the rodent is exposed to two similar objects. There is an inter-trial interval (24 hours) and one of the objects is replaced with a novel object. A "recognition index" is thus calculated as a percentage of time the rodent explores the new object compared with the familiar one. ${ }^{53}$

\section{Y-maze}

The Y-maze is a relatively simple behavioral test meant to quantify working memory and anxiety in rodents. Therefore, this assay might have an advantage in that dementia and anxiety are often comorbid. ${ }^{54}$ Similar to the NOR task, the Y-maze test utilizes rodents' natural exploratory tendency and there is minimal human interaction with the animal. In keeping with its name, the Y-maze contains three identical arms with high walls (Figure 1E). In trial number 1, one arm is blocked (the novel arm) and the rodent explores for 5 minutes. In trial 2 , the rodent freely moves among all the three arms. The general premise of the second trial is that mice will remember the previously explored arms while entering the novel arm a higher number of times, commonly termed "spontaneous alteration." 55

\section{Fear conditioning (FC)}

FC (Figure 1F) is a widely used behavioral memory test in rodents because of its Pavlovian nature and its relative ease of performance. FC is in a general sense similar to the "eye-blink" associative learning paradigm seen in humans and primates, where adverse events are learned quickly and anticipated. ${ }^{56}$ Studies have indicated that classical conditioning and amygdala-dependent $\mathrm{FC}$ are impaired in AD patients. ${ }^{57}$ The basic FC protocol is to place rodents in an enclosed box on an electrified wire floor. After a brief exploration period, a series of audible tones/bright lights are presented and followed by mild foot shocks (pain). The rodents are then removed from the box for a certain time interval (usually 24 hours) and then placed back into the box. The same tone is presented and the measure of learning is quantified by how quickly, and to what extent, the rodent freezes after exposure. ${ }^{58}$

\section{IntelliCage and touch screen}

Novel behavioral assessing technologies are under development and therefore not currently used in the context of nutritional interventions. However, those technologies may be beneficial to further investigate the roles of nutrition in rodent memory. One tool is the rodent touch screen which is a useful tool for assessing working memory. ${ }^{59}$ Another powerful tool is the IntelliCage which can be used for a variety of learning and memory paradigms. ${ }^{60}$ After a time of extensive training, the touch screen and IntelliCage paradigms are heavily automated and therefore greatly reduce experimenter interference. 


\section{The impact of CR and IF on memory acquisition during aging in rodents}

$\mathrm{CR}$ and IF positively affect MWM, BM, and RAWM performance under a variety of conditions and ages in rodents. ${ }^{61}$ Recent studies have demonstrated that CR improved proximity and time to reach the escape platform in the MWM task highlighting improved spatial discrimination. ${ }^{62}$ In another study, short-term CR (28 days) significantly decreased the time necessary to reach the escape platform, and animals spent significantly more time in the target quadrant during the probe trial.$^{63}$ Furthermore, it was demonstrated that exercise training plus CR enhanced rat spatial memory in the MWM, possibly due to upregulation of brain-derived neurotrophic factor (BDNF) ${ }^{64}$ In a transgenic mouse model of $\mathrm{AD}, 1$ year of $40 \%$ CR or every other day IF ameliorated spatial memory acquisition and retention in the MWM. ${ }^{65}$

In the BM, 11 months of IF significantly improved spatial acquisition and the time necessary to reach the escape hole when compared with those mice fed the same diet ad libitum. ${ }^{66}$ In another study, short-term (6 weeks) IF did not improve RAWM memory acquisition in mice and did not significantly change hippocampal BDNF levels. ${ }^{67}$ The results were similar to another study where starting $\mathrm{CR}$ at 6 months of age did not improve spatial memory in old rats.$^{68}$ Conversely, another study showed that CR significantly improved RAWM performance in rats possibly by the upregulation of BDNF. ${ }^{69}$ Approximately, $40 \% \mathrm{CR}$ for 3 months significantly improved RAWM performance in a rat model of cerebral ischemia. ${ }^{70}$

Spatial memory is one of the most widely studied forms of memory in animal models, although there are other forms of memory that must be taken into consideration to capture the full scope of memory loss that occurs during aging and neurodegenerative states. Associative and recognition memory, for example, are important to study as those forms of memory loss often occur either in conjunction with, or prior to, the loss of spatial memory in AD. ${ }^{71}$ Familiar object detection, a form of recognition memory, is known to deteriorate in early stages of $\mathrm{AD} .{ }^{72}$ Patients may not recognize physical objects that they recently encountered, and in very late stages of the disease those "objects" include those experienced regularly throughout life, including the faces of family members and friends. This is often termed "associative memory," and it has been suggested that this effectively paired with working memory. ${ }^{73}$ One form of associative memory has led to the paired associates learning task in humans, which tests the ability to remember the location of objects in the environment. ${ }^{74}$ Those types of associative and working memory, often called "executive function," decline progressively in dementia. ${ }^{75}$

The Y-maze has been used to evaluate effects of nutritional interventions on working memory. One study demonstrated that $20 \%$ and $35 \% \mathrm{CR}$ for 3 months significantly improved learning in male Kunmin mice. ${ }^{76}$ In another study, a periodic diet designed to mimic fasting improved spontaneous alternation behavior in 23-month-old mice. ${ }^{77}$ One study that investigated a $40 \%$ lifelong CR treatment in rats showed a decrease in NOR in the CR group, suggesting that $\mathrm{CR}$ treatment worsened NOR performance. ${ }^{62}$ Another study demonstrated that longterm CR improved NOR memory in old LOU/C/Jall (LOU) rats, which are considered a "gold-standard" for aging research because they live much longer than other strains. ${ }^{78}$

There have been a variety of nutritional studies which utilized FC for assessing memory. One recent study suggested that hunger may play a critical role in the formation of fear-related contextual and cued memory by strengthening amygdala connections - more specifically the basolateral nucleus and central amygdala, both of which are involved in fear extinction learning. One recent study confirmed these results, where the deletion of the hunger gene Y4 reduced appetite and impaired the $\mathrm{FC}$ response in mice. Interestingly, this result was reversed by fasting, as quantified by FC. ${ }^{79}$ Other studies have confirmed those results, for example, CR significantly improved contextual freezing behavior in a mouse model of AD.$^{80}$ Another genetic study showed that $\mathrm{CR}$ ameliorated freezing behavior seen in presenilin-1 and -2 double knockout mice ${ }^{81}$ With regard to amino acids, one study looked at the effects of limiting dietary Trp intake for at least 1 month in young mice and assessing FC responses, concluding that Trp is essential in the formation of hippocampal contextual and cued memory formation. ${ }^{82}$

\section{Influence of individual macronutrients on learning and memory in rodents}

The limited number of studies looking at macronutrient ratios in mouse memory acquisition highlights the need for further investigation in that area. While there have been limited interventional studies in this regard, there is information on the general roles of single macronutrients on cognition. ${ }^{83}$

\section{Protein and amino acids}

Dietary protein restriction can extend lifespan in a range of organisms, including rodents. ${ }^{84}$ Cycles of dietary protein restriction ameliorated working memory deficits evaluated in the Y-maze and lessened hyperphosphorylated Tau levels 
without affecting $A \beta$ levels. ${ }^{85}$ Conversely, a high-protein diet worsened memory acquisition in male Wistar rats in the MWM.$^{86}$ Most of the studies on dietary amino acids and cognition have focused on $\operatorname{Trp}$ because it is a precursor to serotonin, which is a neurotransmitter that regulates learning and memory, and mood. ${ }^{87}$ When rats were maintained on a Trp-deficient diet during the first 2 postnatal months, they exhibited impaired memory acquisition in the MWM. ${ }^{88}$ BDNF likely plays a role in the beneficial effects of dietary Trp on cognition because serotonergic synaptic activity increases BDNF expression. ${ }^{89}$ Indeed, it was recently reported that dietary Trp supplementation increases BDNF expression in the hippocampus and frontal cortex of aged rats..$^{90}$

\section{Fat}

It is a well-established fact that excessive and chronic high-fat diet (HFD) hinders rodent memory performance and injures hippocampal neurons in many strains of mice and rats. ${ }^{91,92}$ It was recently shown that an energy-dense diet worsens cognitive decline in a rat model of AD by increasing the levels of amyloid precursor protein and dysregulation of the sirtuin pathways. ${ }^{93}$ In another study, a 3-month HFD period significantly increased the proinflammatory cytokine profile in mice and impaired NOR test performance. ${ }^{94}$ A chronic HFD results in impaired short- and long-term memory in mice as measured by NOR and MWM, possibly due in part to impaired hippocampal insulin signaling. $\mathrm{CR}$ can attenuate the adverse effects of a HFD on cognition. ${ }^{95}$

\section{Carbohydrate}

Chronically excessive glucose or fructose intake impairs synaptic plasticity and cognition by mechanisms involving the production of proinflammatory factors, insulin resistance, and glucose metabolism dysregulation, possibly contributing to the development of $\mathrm{AD}$ and other neurodegenerative diseases. ${ }^{96,97}$ Poor glycemic control and type-2 diabetes may accelerate the onset of dementia during aging. ${ }^{98}$ IF is believed to enhance hippocampal synaptic plasticity and cognitive performance, in part, by elevation of the circulating ketone beta-hydroxybutyrate which is not only an energy substrate for neurons but also induces the expression of BDNF. ${ }^{99,100}$ It was recently reported that a ketone ester diet can ameliorate learning and memory deficits and lessen anxiety in a mouse model of AD. ${ }^{101}$

\section{Conclusion and future research}

Nutrition influences brain aging. CR and IF are two robust interventions that positively impact the aging brain. Studies to date have not addressed the issue of dietary nutrient balance on the aging brain. There is mounting evidence that the ratios and amounts of individual macronutrients influence late-life cardiometabolic health and lifespan and do so via similar metabolic molecular pathways as CR and IF. Nutritional geometry offers an integrative framework for designing, interpreting, and implementing dietary studies that explore the main and interactive effects of different nutrients, and offers a powerful tool for future research into brain health. ${ }^{102-104}$

Regarding experimental tools, rodent behavioral testing provides a useful model for assessing the role of nutrition in brain health. There are a variety of behavioral assays available to assess those changes, each with their strengths and limitations. We suggest that the establishment of cooperative efforts and agreement among scientists with regard to rodent behavioral testing will help to "bridge the gap" in nutritional cognitive research. Those collaborative efforts will help establish similarities and differences in determining the effects of various nutritional interventions on rodent memory.

\section{Acknowledgments}

We thank the coauthors in studies cited in this review. We also would like to thank Dr Rahul Gokarn for his valuable contributions to the manuscript.

This work was supported by the Aging and Alzheimer's Research Institute, National Health and Research Council of Australia (NHMRC) (grant numbers 571328 and 1084267); the Intramural Program of the National Institute on Aging, NIH (RdC and MPM); the American Australian Association (AAA) Education Fund (DW); and the NHMRC Peter Doherty Early Career Fellowship (grant number 1110098) (SMS-B).

\section{Disclosure}

The authors report no conflicts of interest in this work.

\section{References}

1. Kaeberlein M, Rabinovitch PS, Martin GM. Healthy aging: the ultimate preventative medicine. Science. 2015;350(6265):1191-1193.

2. Waite LM. Treatment for Alzheimer's disease: has anything changed? Aust Prescr. 2015;38(2):60-63.

3. de Cabo R, Carmona-Gutierrez D, Bernier M, Hall MN, Madeo F. The search for antiaging interventions: from elixirs to fasting regimens. Cell. 2014;157(7):1515-1526.

4. Le Couteur DG, Solon-Biet S, Cogger VC, et al. The impact of lowprotein high-carbohydrate diets on aging and lifespan. Cell Mol Life Sci. 2016;73(6):1237-1252.

5. Le Couteur DG, Solon-Biet S, Wahl D, et al. New horizons: dietary protein, ageing and the Okinawan ratio. Age Ageing. 2016;45(4):443-447. 
6. Sirois C, Laroche ML, Guenette L, Kroger E, Cooper D, Emond V. Polypharmacy in multimorbid older adults: protocol for a systematic review. Syst Rev. 2017;6:104.

7. Mattson MP, Longo VD, Harvie M. Impact of intermittent fasting on health and disease processes. Ageing Res Rev. 2016;31(16):30251-30253.

8. Solon-Biet SM, Mitchell SJ, de Cabo R, Raubenheimer D, Le Couteur DG, Simpson SJ. Macronutrients and caloric intake in health and longevity. J Endocrinol. 2015;226(1):R17-R28.

9. Vaiserman AM, Lushchak OV, Koliada AK. Anti-aging pharmacology: promises and pitfalls. Ageing Res Rev. 2016;31:9-35.

10. Solon-Biet SM, Walters KA, Simanainen UK, et al. Macronutrient balance, reproductive function, and lifespan in aging mice. Proc Natl Acad Sci U S A. 2015;112(11):3481-3486.

11. Ingram DK, Anson RM, de Cabo R, et al. Development of calorie restriction mimetics as a prolongevity strategy. Ann N Y Acad Sci. 2004:412-423.

12. Mercken EM, Carboneau BA, Krzysik-Walker SM, de Cabo R. Of mice and men: the benefits of caloric restriction, exercise, and mimetics. Ageing Res Rev. 2012;11(3):390-398.

13. Raubenheimer D, Simpson SJ, Le Couteur DG, Solon-Biet SM, Coogan SC. Nutritional ecology and the evolution of aging. Exp Gerontol. 2016;86:50-61.

14. Solon-Biet SM, McMahon AC, Ballard JW, et al. The ratio of macronutrients, not caloric intake, dictates cardiometabolic health, aging, and longevity in ad libitum-fed mice. Cell Metab. 2014;19(3):418-430.

15. Pan H, Finkel T. Key proteins and pathways that regulate lifespan. J Biol Chem. 2017;292(16):6452-6460.

16. Anson RM, Guo Z, de Cabo R, et al. Intermittent fasting dissociates beneficial effects of dietary restriction on glucose metabolism and neuronal resistance to injury from calorie intake. Proc Natl Acad Sci US A. 2003;100(10):6216-6220.

17. Johnson JE, Johnson FB. Methionine restriction activates the retrograde response and confers both stress tolerance and lifespan extension to yeast, mouse and human cells. PLoS One. 2014;9(5):e97729.

18. Ables GP, Johnson JE. Pleiotropic responses to methionine restriction. Exp Gerontol. 2017;17(17):83-88.

19. Brown-Borg HM, Buffenstein R. Cutting back on the essentials: can manipulating intake of specific amino acids modulate health and lifespan? Ageing Res Rev. 2016;26(16):30204-30205.

20. Kadish I, Kumar A, Beitnere U, Jennings E, McGilberry W, van Groen T. Dietary composition affects the development of cognitive deficits in WT and Tg AD model mice. Exp Gerontol. 2016;86:39-49.

21. Simpson SJ, Le Couteur DG, Raubenheimer D, et al. Dietary protein, aging and nutritional geometry. Ageing Res Rev. 2017;39:78-86.

22. Wahl D, Cogger VC, Solon-Biet SM, et al. Nutritional strategies to optimise cognitive function in the aging brain. Ageing Res Rev. 2016;31:80-92.

23. Hall RD. Is hippocampal function in the adult rat impaired by early protein or protein-calorie deficiencies? Dev Psychobiol. 1983;16(5):395-411.

24. Mattson MP. Energy intake and exercise as determinants of brain health and vulnerability to injury and disease. Cell Metab. 2012;16(6): 706-722.

25. Mattson MP. The impact of dietary energy intake on cognitive aging. Front Aging Neurosci. 2010;2(5).

26. Stranahan AM, Mattson MP. Recruiting adaptive cellular stress responses for successful brain ageing. Nat Rev Neurosci. 2012;13(3):209-216.

27. Raefsky SM, Mattson MP. Adaptive responses of neuronal mitochondria to bioenergetic challenges: roles in neuroplasticity and disease resistance. Free Radic Biol Med. 2017;102:203-216.

28. Maswood N, Young J, Tilmont E, et al. Caloric restriction increases neurotrophic factor levels and attenuates neurochemical and behavioral deficits in a primate model of Parkinson's disease. Proc Natl Acad Sci US A. 2004;101(52):18171-18176.

29. Mattison JA, Colman RJ, Beasley TM, et al. Caloric restriction improves health and survival of rhesus monkeys. Nat Commun. 2017;8:14063.

30. Willette AA, Coe CL, Birdsill AC, et al. Interleukin-8 and interleukin-10, brain volume and microstructure, and the influence of calorie restriction in old rhesus macaques. Age. 2013;35(6):2215-2227.
31. Burke SN, Ryan L, Barnes CA. Characterizing cognitive aging of recognition memory and related processes in animal models and in humans. Front Aging Neurosci. 2012;4:15.

32. Engle JR, Barnes CA. Characterizing cognitive aging of associative memory in animal models. Front Aging Neurosci. 2012;4:10.

33. Foster TC, Defazio RA, Bizon JL. Characterizing cognitive aging of spatial and contextual memory in animal models. Front Aging Neurosci. 2012;4:12.

34. Kosik KS, Rapp PR, Raz N, Small SA, Sweatt JD, Tsai LH. Mechanisms of age-related cognitive change and targets for intervention: epigenetics. J Gerontol A Biol Sci Med Sci. 2012;67(7):741-746.

35. Welsh K, Butters N, Hughes J, Mohs R, Heyman A. Detection of abnormal memory decline in mild cases of Alzheimer's disease using CERAD neuropsychological measures. Arch Neurol. 1991;48(3):278-281.

36. Webster SJ, Bachstetter AD, Nelson PT, Schmitt FA, Van Eldik LJ. Using mice to model Alzheimer's dementia: an overview of the clinical disease and the preclinical behavioral changes in 10 mouse models. Front Genet. 2014;5(88).

37. Klencklen G, Despres O, Dufour A. What do we know about aging and spatial cognition? Reviews and perspectives. Ageing Res Rev. 2012; 11(1):123-135

38. Lithfous S, Dufour A, Despres O. Spatial navigation in normal aging and the prodromal stage of Alzheimer's disease: insights from imaging and behavioral studies. Ageing Res Rev. 2013;12(1):201-213.

39. Hodges H. Maze procedures: the radial-arm and water maze compared. Brain Res Cogn Brain Res. 1996;3(3-4):167-181.

40. Vorhees CV, Williams MT. Morris water maze: procedures for assessing spatial and related forms of learning and memory. Nat Protoc. 2006;1(2):848-858.

41. Morris R. Developments of a water-maze procedure for studying spatial learning in the rat. J Neurosci Methods. 1984;11(1):47-60.

42. Rosenfeld CS, Ferguson SA. Barnes maze testing strategies with small and large rodent models. J Vis Exp. 2014;(84):51194.

43. Barnes CA. Memory deficits associated with senescence: a neurophysiological and behavioral study in the rat. J Comp Physiol Psychol. 1979;93(1):74-104.

44. Akirav I, Sandi C, Richter-Levin G. Differential activation of hippocampus and amygdala following spatial learning under stress. Eur $J$ Neurosci. 2001;14(4):719-725.

45. Vorhees CV, Williams MT. Assessing spatial learning and memory in rodents. ILAR J. 2014;55(2):310-332.

46. Harrison FE, Hosseini AH, McDonald MP. Endogenous anxiety and stress responses in water maze and Barnes maze spatial memory tasks. Behav Brain Res. 2009;198(1):247-251.

47. Shukitt-Hale B, McEwen JJ, Szprengiel A, Joseph JA. Effect of age on the radial arm water maze-a test of spatial learning and memory. Neurobiol Aging. 2004;25(2):223-229.

48. Penley SC, Gaudet CM, Threlkeld SW. Use of an eight-arm radial water maze to assess working and reference memory following neonatal brain injury. J Vis Exp. 2013;(82):50940.

49. Wolf A, Bauer B, Abner EL, Ashkenazy-Frolinger T, Hartz AM. A comprehensive behavioral test battery to assess learning and memory in 129S6/Tg2576 mice. PLoS One. 2016;11(1):e0147733.

50. Leger M, Quiedeville A, Bouet V, et al. Object recognition test in mice. Nat Protoc. 2013;8(12):2531-2537.

51. Bevins RA, Besheer J. Object recognition in rats and mice: a one-trial non-matching-to-sample learning task to study "recognition memory". Nat Protoc. 2006;1(3):1306-1311.

52. Bengoetxea X, Rodriguez-Perdigon M, Ramirez MJ. Object recognition test for studying cognitive impairments in animal models of Alzheimer's disease. Front Biosci. 2015;7:10-29.

53. Wang K, Lu JM, Xing ZH, et al. Effect of $1.8 \mathrm{GHz}$ radiofrequency electromagnetic radiation on novel object associative recognition memory in mice. Sci Rep. 2017;7(44521).

54. Goodarzi Z, Mele B, Guo S, et al. Guidelines for dementia or Parkinson's disease with depression or anxiety: a systematic review. BMC Neurol. 2016;16(1):244. 
55. Conrad CD, Lupien SJ, Thanasoulis LC, McEwen BS. The effects of type I and type II corticosteroid receptor agonists on exploratory behavior and spatial memory in the Y-maze. Brain Res. 1997;759(1):76-83.

56. Curzon P, Rustay NR, Browman KE. Frontiers in neuroscience cued and contextual fear conditioning for rodents. In: Buccafusco JJ, editor. Methods of Behavior Analysis in Neuroscience. Boca Raton: CRC Press/ Taylor \& Francis Group, LLC.; 2009.

57. Gold CA, Budson AE. Memory loss in Alzheimer's disease: implications for development of therapeutics. Expert Rev Neurother. 2008;8(12): 1879-1891.

58. Lugo JN, Smith GD, Holley AJ. Trace fear conditioning in mice. J Vis Exp. 2014;(85):51180.

59. Kwak C, Lim CS, Kaang BK. Development of a touch-screen-based paradigm for assessing working memory in the mouse. Exp Neurobiol. 2015;24(1):84-89.

60. Holter SM, Garrett L, Einicke J, et al. Assessing cognition in mice. Curr Protoc Mouse Biol. 2015;5(4):331-358.

61. Stewart J, Mitchell J, Kalant N. The effects of life-long food restriction on spatial memory in young and aged Fischer 344 rats measured in the eight-arm radial and the Morris water mazes. Neurobiol Aging. 1989;10(6):669-675.

62. Carter CS, Leeuwenburgh C, Daniels M, Foster TC. Influence of calorie restriction on measures of age-related cognitive decline: role of increased physical activity. J Gerontol A Biol Sci Med Sci. 2009; 64(8):850-859.

63. Kishi T, Hirooka Y, Nagayama T, et al. Calorie restriction improves cognitive decline via up-regulation of brain-derived neurotrophic factor: tropomyosin-related kinase B in hippocampus of obesity-induced hypertensive rats. Int Heart J. 2015;56(1):110-115.

64. Kishi T, Sunagawa K. Exercise training plus calorie restriction causes synergistic protection against cognitive decline via up-regulation of BDNF in hippocampus of stroke-prone hypertensive rats. Conf Proc IEEE Eng Med Biol Soc. 2012;7(10):6347547.

65. Halagappa VK, Guo Z, Pearson M, et al. Intermittent fasting and caloric restriction ameliorate age-related behavioral deficits in the triple-transgenic mouse model of Alzheimer's disease. Neurobiol Dis. 2007;26(1):212-220.

66. Li L, Wang Z, Zuo Z. Chronic intermittent fasting improves cognitive functions and brain structures in mice. PLoS One. 2013;8(6):e66069.

67. Khabour OF, Alzoubi KH, Alomari MA, Alzubi MA. Changes in spatial memory and BDNF expression to concurrent dietary restriction and voluntary exercise. Hippocampus. 2010;20(5):637-645.

68. Bond NW, Everitt AV, Walton J. Effects of dietary restriction on radialarm maze performance and flavor memory in aged rats. Neurobiol Aging. 1989;10(1):27-30.

69. Alomari MA, Khabour OF, Alzoubi KH, Alzubi MA. Combining restricted diet with forced or voluntary exercises improves hippocampal BDNF and cognitive function in rats. Int $J$ Neurosci. 2016;126(4): 366-373.

70. Roberge MC, Hotte-Bernard J, Messier C, Plamondon H. Food restriction attenuates ischemia-induced spatial learning and memory deficits despite extensive CA1 ischemic injury. Behav Brain Res. 2008;187(1): 123-132.

71. Parra-Damas A, Chen M, Enriquez-Barreto L, et al. CRTC1 function during memory encoding is disrupted in neurodegeneration. Biol Psychiatry. 2017;81(2):111-123.

72. Laatu S, Revonsuo A, Jaykka H, Portin R, Rinne JO. Visual object recognition in early Alzheimer's disease: deficits in semantic processing. Acta Neurol Scand. 2003;108(2):82-89.

73. Polcher A, Frommann I, Koppara A, Wolfsgruber S, Jessen F, Wagner M. Face-name associative recognition deficits in subjective cognitive decline and mild cognitive impairment. $J$ Alzheimers Dis. 2017;56(3): 1185-1196.

74. Barnett JH, Blackwell AD, Sahakian BJ, Robbins TW. The paired associates learning (PAL) test: 30 years of CANTAB translational neuroscience from laboratory to bedside in dementia research. Curr Top Behav Neurosci. 2016;28:449-474.
75. Baddeley AD, Bressi S, Della Sala S, Logie R, Spinnler H. The decline of working memory in Alzheimer's disease. A longitudinal study. Brain. 1991;114(Pt 6):2521-2542.

76. Wu A, Wan F, Sun X, Liu Y. Effects of dietary restriction on growth, neurobehavior, and reproduction in developing Kunmin mice. Toxicol Sci. 2002;70(2):238-244.

77. Brandhorst S, Choi IY, Wei M, et al. A periodic diet that mimics fasting promotes multi-system regeneration, enhanced cognitive performance and healthspan. Cell Metab. 2015;22(1):86-99.

78. Menard C, Quirion R, Bouchard S, Ferland G, Gaudreau P. Glutamatergic signaling and low prodynorphin expression are associated with intact memory and reduced anxiety in rat models of healthy aging. Front Aging Neurosci. 2014;6(81).

79. Verma D, Wood J, Lach G, Herzog H, Sperk G, Tasan R. Hunger promotes fear extinction by activation of an amygdala microcircuit Neuropsychopharmacology. 2016;41(2):431-439.

80. Brownlow ML, Joly-Amado A, Azam S, et al. Partial rescue of memory deficits induced by calorie restriction in a mouse model of tau deposition. Behav Brain Res. 2014;271:79-88.

81. Wu P, Shen Q, Dong S, Xu Z, Tsien JZ, Hu Y. Calorie restriction ameliorates neurodegenerative phenotypes in forebrain-specific presenilin-1 and presenilin-2 double knockout mice. Neurobiol Aging. 2008;29(10):1502-1511.

82. Uchida S, Umeeda H, Kitamoto A, Masushige S, Kida S. Chronic reduction in dietary tryptophan leads to a selective impairment of contextual fear memory in mice. Brain Res. 2007;29:149-156.

83. Bourre JM. Effects of nutrients (in food) on the structure and function of the nervous system: update on dietary requirements for brain. Part 2 : macronutrients. J Nutr Health Aging. 2006;10(5):386-399.

84. Mirzaei H, Suarez JA, Longo VD. Protein and amino acid restriction, aging and disease: from yeast to humans. Trends Endocrinol Metab. 2014;25(11):558-566.

85. Parrella E, Maxim T, Maialetti F, et al. Protein restriction cycles reduce IGF-1 and phosphorylated Tau, and improve behavioral performance in an Alzheimer's disease mouse model. Aging cell. 2013;12(2):257-268.

86. Mendez-Lopez M, Mendez M, Arias J, Arias JL. Effects of a high protein diet on cognition and brain metabolism in cirrhotic rats. Physiol Behav. 2015;149:220-228.

87. Roberts AJ, Hedlund PB. The 5-HT(7) receptor in learning and memory. Hippocampus. 2012;22(4):762-771.

88. Olvera-Cortes E, Perez-Vega MI, Barajas-Lopez G, Del AngelMeza AR, Gonzalez-Burgos I, Feria-Velasco A. Place learning impairment in chronically tryptophan-restricted rats. Nutr Neurosci. 1998; 1(3):223-235.

89. Mattson MP, Maudsley S, Martin B. A neural signaling triumvirate that influences ageing and age-related disease: insulin/IGF-1, BDNF and serotonin. Ageing Res Rev. 2004;3(4):445-464.

90. Musumeci G, Castrogiovanni P, Szychlinska MA, et al. Protective effects of high tryptophan diet on aging-induced passive avoidance impairment and hippocampal apoptosis. Brain Res Bull. 2017;128:76-82.

91. Stranahan AM, Norman ED, Lee K, et al. Diet-induced insulin resistance impairs hippocampal synaptic plasticity and cognition in middle-aged rats. Hippocampus. 2008;18(11):1085-1088.

92. Ledreux A, Wang X, Schultzberg M, Granholm AC, Freeman LR. Detrimental effects of a high fat/high cholesterol diet on memory and hippocampal markers in aged rats. Behav Brain Res. 2016;312:294-304.

93. Martino Adami PV, Galeano P, Wallinger ML, et al. Worsening of memory deficit induced by energy-dense diet in a rat model of early-Alzheimer's disease is associated to neurotoxic Abeta species and independent of neuroinflammation. Biochim Biophys Acta. 2017;3: 731-743.

94. Barron AM, Tokunaga M, Zhang MR, Ji B, Suhara T, Higuchi M. Assessment of neuroinflammation in a mouse model of obesity and beta-amyloidosis using PET. J Neuroinflammation. 2016;13(1):221.

95. Sims-Robinson C, Bakeman A, Bruno E, et al. Dietary reversal ameliorates short- and long-term memory deficits induced by high-fat diet early in life. PLoS One. 2016;11(9):e0163883. 
96. Hsu TM, Konanur VR, Taing L, et al. Effects of sucrose and high fructose corn syrup consumption on spatial memory function and hippocampal neuroinflammation in adolescent rats. Hippocampus. 2015;25(2):227-239.

97. Arrieta-Cruz I, Gutierrez-Juarez R. The role of insulin resistance and glucose metabolism dysregulation in the development of Alzheimer's disease. Rev Invest Clin. 2016;68(2):53-58.

98. Sheen YJ, Sheu WH. Association between hypoglycemia and dementia in patients with type 2 diabetes. Diabetes Res Clin Pract. 2016;116:279-287.

99. Marosi K, Kim SW, Moehl K, et al. 3-Hydroxybutyrate regulates energy metabolism and induces BDNF expression in cerebral cortical neurons. J Neurochem. 2016;139(5):769-781.

100. Sleiman SF, Henry J, Al-Haddad R, et al. Exercise promotes the expression of brain derived neurotrophic factor (BDNF) through the action of the ketone body beta-hydroxybutyrate. Elife. 2016;5. pii: e15092.

101. Kashiwaya Y, Bergman C, Lee JH, et al. A ketone ester diet exhibits anxiolytic and cognition-sparing properties, and lessens amyloid and tau pathologies in a mouse model of Alzheimer's disease. Neurobiol Aging. 2013;34(6):1530-1539.
102. Raubenheimer D, Simpson SJ. Nutritional ecology and human health. Annu Rev Nutr. 2016;36:603-626.

103. Simpson SJ, Raubenheimer D. Macronutrient balance and lifespan. Aging. 2009;1(10):875-880.

104. Simpson SJ, Raubenheimer D. Caloric restriction and aging revisited: the need for a geometric analysis of the nutritional bases of aging. J Gerontol A, Biol Sci Med Sci. 2007;62(7):707-713.

105. Burgess N, Maguire EA, O'Keefe J. The human hippocampus and spatial and episodic memory. Neuron. 2002;35(4):625-641.

106. Pattwell SS, Bath KG. Emotional learning, stress, and development: an ever-changing landscape shaped by early-life experience. Neurobiol Learn Mem. 2017;27(17):36-48.

107. Daldrup T, Remmes J, Lesting J, et al. Expression of freezing and fear-potentiated startle during sustained fear in mice. Genes Brain Behav. 2015;14(3):281-291.

108. Alamed J, Wilcock DM, Diamond DM, Gordon MN, Morgan D. Two-day radial-arm water maze learning and memory task; robust resolution of amyloid-related memory deficits in transgenic mice. Nat Protoc. 2006;1(4):1671-1679.
Clinical Interventions in Aging

\section{Publish your work in this journal}

Clinical Interventions in Aging is an international, peer-reviewed journal focusing on evidence-based reports on the value or lack thereof of treatments intended to prevent or delay the onset of maladaptive correlates of aging in human beings. This journal is indexed on PubMed Central, MedLine,

\section{Dovepress}

CAS, Scopus and the Elsevier Bibliographic databases. The manuscript management system is completely online and includes a very quick and fair peer-review system, which is all easy to use. Visit http://www.dovepress. com/testimonials.php to read real quotes from published authors. 